Psychology of Language and Communication 2022, Vol. 26, No. 1

Sciendo

DOI: $10.2478 /$ plc-2022-0001

\author{
Mazin Alqhazo, Firas Alfwaress \\ Rehabilitation Sciences, Jordan University of Science and Technology, Jordan
}

\title{
Stuttering frequency on content and function words in pre-school and school-age Jordanian Arabic-speaking children who stutter
}

\begin{abstract}
This study investigated the influence of loci of content and function words on stuttering frequency in the speech of Arabic children who stutter. Participants were 85 children who stutter ( 24 preschool, 61 school age). The preschool children who stutter were 17 males and 7 females with a mean age of $4.58 \pm 0.50$ (range: $4-5$ years old). The school age children who stutter were 56 males and 5 females with a mean age of $10.64 \pm 2.76$ (range: 6-16 years old). No significant difference was found between the preschool and school age children who stutter in the mean percentage of stuttering on both content and function words. For school age children who stutter, results showed a significantly higher percentage of stuttering on function words compared to content words in the mild level of stuttering $(p=.010)$. Taking severity as a continuous variable, results indicated a significant positive correlation between scores on the Stuttering Severity Instrument-4 (SSI-4) and loci of stuttering on both content and function words. The results also revealed a significant negative correlation between age (as a continuous variable) and loci of stuttering in the category of function words. The findings of the current study provide new information about the impact of word type (function vs. content words) on stuttering in Arabic-speaking children.
\end{abstract}

Key words: stuttering frequency, Arabic-speaking stutterers, content words, function words

Address for correspondence: Mazin Alqhazo, Rehabilitation Sciences, Jordan University of Science and Technology, Irbid, 11183, Irbid, Jordan

E-mail: mtqhazo@just.edu.jo

This is an open access article licensed under the CC BY NC ND 4.0 License. 
The role of linguistic factors such as word type (function and content words) in the frequency of stuttering remains an unresolved issue. It has been argued that disfluencies are more likely to occur on content words than on function words in the speech of adult people who stutter (Brown, 1945). Content words are nouns, verbs, adjectives, and adverbs, whereas prepositions, pronouns, conjunctions, auxiliary verbs, inflections, and interjections are considered function words (Brown \& Fraser, 1963). Content words belong to an "open" linguistic set which contains a large number of words that are infrequently used in speech. Function words belong to a "closed" linguistic set which contains a limited number of words that are frequently used in speech. In addition, the prosodic features of function words are characterized by minimal stress on syllables, flat fundamental frequency registers, and smooth vowel transitions compared to content words (Bard \& Anderson, 1983).

The distinction between the frequencies of stuttering on content versus function words has been frequently examined (Au-Yeung et al., 1998; Bergmann, 1986; Natke et al., 2002; Bloodstein \& Grossman, 1981; Koopmans et al., 1991; Wingate, 1979). However, they have yielded mixed results. Some studies have shown a higher frequency of stuttering on content words (Au-Yeung et al., 1998; Bergmann, 1986; Natke et al., 2002) especially in adult stutterers. On the other hand, Bloodstein and Grossman (1981) have reported that children who stutter are more likely to be disfluent on function words whereas other studies have shown no differences (Koopmans et al., 1991; Wingate, 1979). This variability could be explained by the methodological designs used. For example, studies such as $\mathrm{Au}-$ Yeung et al. (1998) used spontaneous speech recordings where the durations of pauses and prolonged segments were included in the analyses. Prosodic features such as tone levels, primary stress, secondary stress, and tone unit boundaries were used to classify words into function or content. Single word answers, such as yes or no were excluded from the analyses. In other studies, such as Bloodstein an Grossman (1981), pauses and secondary features were excluded from the analyses and utterances that were not spontaneous, such as the response "blue" to the question "what color is it?", were also excluded.

Other factors might be owing to the inevitable nature of stuttering that is characterized by unpredictable, variable, and changeable presentations and severity. At the same time, there are similarities among the different patterns of stuttering.

Because various definitions of stuttering have been suggested (Martin \& Haroldson, 1981; Wingate, 1964), some have argued that it may be difficult to agree on accurate criteria for counting stuttering. The topics of discussion included the unit of measurement (moments of stuttering vs. duration of time), the exact behaviors to be measured (only stuttered disfluencies vs. a broad range of all disfluency types), the types of disfluencies, and the reliability and validity of various measurement techniques (Yaruss, 1997).

The current study tried to fill the gaps in the previous literature by counting the moments of stuttering based on Yairi's (1997) classification of stuttering-like 
dysfluencies. These moments included prolongations (if they exceeded $50 \mathrm{~ms}$ ), blocks (if they exceeded $50 \mathrm{~ms}$ ), repetitions of sounds, repetitions of syllables, and repetitions of one-syllable words. Whole word, phrase, and sentence repetitions were counted as normal dysfluencies. Hesitations were considered normal and were excluded form disfluency analyses if they occured without physical features.

The other reason for variability in results is the effect of linguistic factors on the frequency of stuttering, which has not been investigated clearly. Content and function words are linguistically discrepant and lack the similarity and balance in terms of the representation of linguistic factors such as word length, phonetic structure, word stress, word frequency, and the information load. Brown (1945) identified four different types of words in which adult stutterers tend to exhibit frequent stuttering: (a) content words rather than function words, (b) words in the initial position in a sentence, (c) words with initial consonant sounds, and (d) long words. Attempts to associate the effect of phonological development with stuttering frequency without careful consideration of the syntactic and pragmatic aspects of language encountered difficulties (Brown, 1945). This intimate overlap among language dimensions and phonology makes the distinction more complicated, especially with the observed inherent characteristic that most frequently stuttered words usually begin a sentence. These characteristics include words with a consonant as initial sound, longer words, and words which carry major information, regardless of the phonological classes to which those sounds belong.

Content words are typically multisyllabic, more complex, carry primary stress, have late emerging consonants (LEC) as the initial sounds, and have LEC strings compared to function words (Dayalu et al., 2002; Howell et al., 1999). In the existing literature, it is uncommon to find reports that study the impact of word-final phonology, although some studies have focused on other aspects of phonology. It is considered hard to separate word-final phonology from inflectional morphology since the word-final morphophonological segments are the same set of segments serving two different language parameters. Marshall (2004) concluded that phonological and morphological complexity at wordfinal positions do not impact the stuttering rate of English speaking adults, and reported that a small proportion of adults and children showed stuttering over complex morphological words in an elicitation task. Research has shown that stutterers usually have a tendency to stutter on the same words repeatedly to the extent that a certain degree of anticipation might take place (Alm, 2004; Arenas, 2012; Brocklehurst et al., 2013). Stutterers can foresee the words where a stuttering moment will arise; this feature of stuttering becomes more accurate with the maturation of a child's phonology over age.

Some previous studies tried to control independent variables in an attempt to evaluate the grammatical effect of word category more precisely. For example, some reports used structured lists of equal content and function words that have been matched for initial sounds and number of syllables (Dyalu et al., 2002). Other authors attempted to study the frequency of stuttering using meaningful and 
nonmeaningful passages. Such reports showed higher stuttering percentages on nonmeaningful lists (Hegde, 1970; Dayalu et al., 2005). However, generalization of such results into real life situations is biased since stutterers tend to use connected speech utterances for communication, not the restricted speech lists.

\section{Arabic Morphology}

Morphologically, words in Arabic are formed nonconcatenatively, which means that morphemes are not linked together in a series or order depending on each other, they are placed over each other based on a triconsonantal root which forms the basic unit for derivation. For example, the word /darasa/ (studied) is derived from the root /d-r-s/. Different but semantically related derivatives could be generated by adding different vowels to the root, for example, /daras/ "studied," /daraso/ "they studied," /durus/ "lessons," /da:ris/ "learner," (Boudelaa \& Marslen-Wilson, 2001).

There are three main sets of words in Arabic: function, content and functioncontent (Abdalla et al., 2010). Function words are a closed set of words that have no full lexical meaning but have grammatical or functional roles. This class includes articles, pronouns, conjunctions, prepositions, auxiliaries, and inflections.

Function words in Arabic are mostly monosyllabic and can occur before and/ or after content words. They are divided into two forms: free (munfas'il) which could stand by themselves such as /min Samma:n/ ("from Amman") and bound (muttas ${ }^{\varsigma}$ il) which are attached to the beginning or the end of other words such as (/Pilbint/, /Pil/ "the" /bint/ "girl"). Content words are an open class set that includes nouns, verbs, adverbs, and adjectives. The function-content words are function words that are attached either before the content words such as /bi/ ("in") that could precede the word /almat'ar airport/, or before and after content words at the same time such as /bi almat'ar aat in the airports/ which are preceded by /bi/ ("in") and followed by the feminine plural suffix /aat/ (Al-Tamimi et al., 2013).

With the morphological system of the Arabic language being different from English, it is important to find the loci of stuttering between Arabic word categories (function vs. content) across different age groups that might contribute cross-linguistic data to the content-function and stuttering debate. There is a major need for evidence-based research concerning stuttering frequency in Arabic speaking stutterers. Limited studies have been conducted with this population. For example, Attieh (2010) examined the loci and frequency of stuttering in function and content words across different age groups among Jordanians. He found that there is a gradual increase in the mean percentages of stuttering along with the increase in word length for all age groups (Group 1: $M_{\text {age }}=7 ; 5$; Group $2: M_{\text {age }}=11 ; 10 ;$ Group $\left.3: M_{\text {age }}=20 ; 7\right)$.

Such evidence will assist speech pathologists in better understanding some 
of the mechanisms of stuttering and provide better care for stutterers. The current study attempts to evaluate the frequency of stuttering in content versus function words in Arabic speaking stutterers. The free forms of function words that could stand by themselves were counted as separate words and included in the analysis of loci of stuttering, the bound forms of function words that are attached to the beginning or the end of other words were not counted as separate words and were excluded from the analysis. The third set of words in Arabic, which is functioncontent, were excluded from the analysis because they are always attached either before or after the content words.

Three specific research questions were tested in this study. First, to what extent does stuttering frequency differ when compared for content words versus function words. Second, to what extent does stuttering frequency differ between content words versus function words when comparing preschool and school age children who stutter. Finally, are there any significant differences in the frequency of stuttering on content and function words when taking severity into consideration.

\section{Method}

\section{Participants}

This study has been approved by the Institutional Review Board at Jordan University of Science and Technology (Ref\# 3/113/2018). Accordingly, assent or consent forms were signed preceding data collection. Participants in this study included 85 children who stutter ( 24 preschool, 61 school age). The preschool children who stutter were 17 males and 7 females with a mean age of $4.58 \pm 0.50 S D$ (range: $4-5$ years old). Five children (20.8\%) had a mild level of stuttering, fifteen children $(62.5 \%)$ had a moderate level of stuttering, and four children (16.6\%) had a severe level of stuttering The school age children who stutter comprised 56 males and 5 females with mean age of $10.64 \pm 2.76$ $S D$ (range: 6-16 years old). Thirty seven children (47\%) had a mild level of stuttering, eighteen children (29.5\%) had moderate level of stuttering, and six children $(9.8 \%)$ had a severe level of stuttering. General characteristics about the participants and their severity according to the Stuttering Severity Instrument-4 (SSI-4) are provided in the Appendix.

All the participants were evaluated and diagnosed by a speech pathologist as exhibiting stuttering disorder. They were recruited from the first visit to the Speech clinic at King Abdulla Hospital before receiving any speech therapy. Patient history showed that all the participants had been diagnosed as having developmental stuttering. Pure tone audiometric screenings showed normal bilateral hearing thresholds for all the participants. The inclusion criteria included participants who were diagnosed as having developmental stuttering, 
ranged in age from 3-16 years, having received no therapy sessions, having a normal hearing threshold, and whose native language is Arabic. The exclusion criteria included a history of any form of communication disorders, a current communication disorder other than stuttering, cognitive deficits of a significant level, and the presence of any substantial health problem. Four subjects did not meet the recruitment criteria, one had unilateral conductive hearing loss, one had a history of language delay, and the other two had speech lisps.

The majority of the participants were male stutterers, which could be explained by the high prevalence of stuttering in males contrasted to females. Participants were from the lower and middle socio-economic classes. They came from the same geographical area and had the same dialect.

\section{Design}

The research design used in this study was a cross-sectional research method based on the fact that all the participants have the disorder (stuttering) at the time of inclusion. Every subject who either came or transferred to the Speech Clinic during the years 2018 and 2019 and met the inclusion criteria was selected for the purpose of the current study.

\section{Severity Measurement}

Before using the SSI-4 to measure stuttering severity, the words in each speech sample were divided into syllables. Syllables in Arabic could be classified into three main categories with six structural types. The first type is the light syllable which consists of a consonant followed by a short vowel (CV), for example, is/ $\mathrm{ka} /$. The second type is the heavy syllable which consists of either a consonant followed by two vowels (CVV), for example, l/ baa/, or of a consonant followed by a short vowel and a consonant (CVC), for example, ب/ bab/. The third category is called the superheavy syllable which consists of a consonant followed by one or two vowels followed by one or two consonants. There are three forms of superheavy syllables in Arabic; CVVC, for example, نون/nuun/, CVVC, for example, موي/yawm/, CVCC, for example, بكا kabb/, and CVVCC, for example, ب/shaabb/ (Halpern, 2009).

The SSI-4 includes four areas of speech behavior. The first area is frequency, measured by counting the number of moments of stuttering in speech samples. Each moment of stuttering during both the reading task and the speaking task for readers was identified (normal disfluencies such as revisions and interjections were excluded), whereas only the speaking task was used for the nonreaders. The total percentage of stuttering for each task was calculated by dividing the total number of stuttering moments by the total number of syllables multiplied by 100 (overall $\%=$ total number of disfluencies/total number of words $\times 100$ ). This percentage was converted to a scale of 2-9 in the reading task, 2-9 in the 
speaking task, and 4-18 in the speaking task for nonreaders. The score in the reading task and the speaking task were summed to obtain the frequency score for readers, whereas the score of the speaking task represents the frequency score for the nonreaders. Duration was the second area of speech behavior, which was timed to the nearest one tenth of a second and converted to scale scores of 2-18. The average length of three longest moments of stuttering were calculated using a stop watch. Physical concomitants were the third area of speech behavior, evaluated using a scale from 0 (none) to 5 as (severe and painful) in four areas of physical features (distracting sounds, facial grimaces, head movements, and movements of extremities). The scores of all aspects were added and converted to scale scores of 0-20. The total scores of frequency, duration, and physical concomitants were converted into percentile equivalents of severity ratings according to age.

\section{Data Collection}

A VHS Panasonic video camera was used to obtain videotape recordings of the speech of subjects in the speaking task. All subjects were asked to talk about a cartoon story of their choice because telling a story about a cartoon may be more involved in terms of memory and language complexity. The video recordings focused on the subject's head and also showed the trunk and upper limbs. Recordings were obtained in a relaxed atmosphere in one of the therapy rooms at the speech clinic of King Abdullah Hospital. Narrow phonetic transcriptions were used to document the observed moments of stuttering behavior. Targeted stuttering behaviors were defined as prolongations, blocks, repetitions of sounds, repetitions of syllables, and repetitions of one-syllable words, which represent Yairi's (1997) classification of stuttering-like dysfluencies. Both prolongations and blocks were counted if they exceeded $50 \mathrm{~ms}$. Spectrographic analyses were done to measure the time duration of prolongation and block moments using the Computerized Speech Laboratory model 6400 manufactured by Kay Elemetrics. Stuttered words were classified into content and function words by two speech pathologists. Whole word, phrase, and sentence repetitions were counted as normal dysfluencies. Therefore, these behaviors were not counted to show the frequency of stuttering behavior and accordingly were not considered in the analysis. Hesitations were considered normal if they appeared relaxed and not associated with concomitant physical or body movements. The total number of both content and function words as well as the number of content and function words with stuttering were counted in each speaking sample. The frequency of stuttering on content words was calculated by dividing the number of content words with stuttering by the total number of all content words and multiplying the result by 100 (overall \% = number of stuttering on content words/total number of all content words $\times 100$ ). The same formula was applied for the frequency of function words. These percentages were inserted into SPSS Version 22 for further analyses. 


\section{Reliability Measures}

Interrater reliability is an important criterion to be considered when judgment of observers is involved (Di Iorio, 2005). It is usually assessed by ascertaining agreement or consistency between two or more raters. For this study, the assessment was conducted by asking a second speech pathologist to analyze the data of 10 randomly selected participants. The analyses and transcriptions were done independently and compared with the analyses of the first speech pathologist. Pearson's $r$ was used to determine inter-rater reliability. A correlation coefficient of $r=.97$ was achieved. The results indicated $97 \%$ agreement between the Autism Spectrum Disorders 2raters on the identification of stuttering moments and counting the function versus content words across the selected speech samples.

\section{Results}

The average number of content words in all samples was $88.7 \pm 21.5$, rangL $25-$ 135. The average number of function words was 56.1 \pm 21.0 , range: 19-134.

A paired-samples $t$-test was conducted to assess the difference between stuttering frequency on content versus function words in both preschool and school age children who stutter. Results indicated no significant differences (see Table 1).

A paired-samples $t$-test was also ran to evaluate the difference between stuttering frequency on content words versus function words in both preschool and school age children who stutter, taking severity into consideration (see Table 2 ). For preschool children, results indicated no significant differences in the mean percentage of stuttering in all levels of severity. For school age children who stutter, results showed a siginificant higher mean percentage of stuttering on function words compared to content words in the mild level of stuttering $(p=.010)$.

Multiple regression was conducted to assess the impact of severity on the loci of stuttering in each category of words (function or content). Because there were too few participants in some cells (e.g, severe stuttering severity), the SSI4 scores were considered as a continuous rather than categorical variable. The total variance explained by the model was $28 \%, F(2,82)=15.9, p=<.001$. The analysis showed a significant positive correlation between SSI-4 scores of severity and loci of stuttering in the category of content words, $r=.17, n=85$, $p=.05$. Similarly, the results revealed a significant positive correlation between SSI-4 scores and loci of stuttering in the category of function words, $r=.52, n$ $=85, p=.001$. This means that higher percentages of stuttering are expected on both function words and content words with greater levels of severity.

Moreover, multiple regression was conducted to assess the impact of age on the loci of stuttering in each category of words considering age as a continuous variable, because there was a wide age range between groups. Although the model was not significant, explaining just $4 \%$ of the total variance, $F(2,82)=1.9, p=$ .14 , the results showed a negative correlation between age and loci of stuttering 
in the category of content words, $r=.04, n=85, p=.33$. Additionally, the results revealed a significant negative correlation between age and loci of stuttering in the category of function words, $r=.21, n=85, p=.02$. This means that frequency of stuttering decreased as people who stutter got older (see Figures 1 and 2).

Because there is a wide age range in school-age children who stutter (6-16 years), which is concerning given the previous research findings that show a transition from more stuttering on function words to more stuttering on content words occurring at ages beyond 12 (Howell et al., 1999), the school-age children were divided into three age groups: primary $(n=20$, ages 6-9), middle $(n=37$, ages $10-13)$, and secondary $(n=12$, ages $14-16)$. A paired-samples $t$-test was ran to detect any difference between the loci of stuttering in function versus content words in each group. The results indicated no significant differences in the three subgroups of school-age children who stutter.

\section{Discussion}

The main goal of the present study was to explore the frequency of stuttering on content versus function words in the Arabic speaking stutterers taking age and severity into consideration. A spontaneous speech task was implemented to obtain speech samples from the parrticipants. To circumvent bias, we tried to keep the task as natural and representative of ordinary speech as possible and avoid tasks such as reading words from speech lists. It was found that the mean percentages

Table 1. Paired t-Test Between the Mean Percentage of Stuttering on Content and Function Words

\begin{tabular}{|c|c|c|c|c|c|}
\hline Stuttering group & $\begin{array}{c}\text { Mean } \%(S D) \text { of } \\
\text { stuttering on content } \\
\text { words }\end{array}$ & $\begin{array}{c}\text { Mean \% }(S D) \text { of } \\
\text { stuttering on function } \\
\text { words }\end{array}$ & $t$ & $d f$ & $\begin{array}{c}p \\
\text { (two- } \\
\text { tailed) }\end{array}$ \\
\hline Preschool $(n=24)$ & $16.5 \%(8.7)$ & $19.2 \%(10.8)$ & 1.12 & 23 & .275 \\
\hline School-age $(n=61)$ & $17.0 \%(42.2)$ & $16.5 \%(10.9)$ & 0.11 & 60 & .915 \\
\hline
\end{tabular}

Table 2. Paired t-Test Between the Mean Percentage of Stuttering on Content and Function Words According to Severity

\begin{tabular}{|c|c|c|c|c|c|c|}
\hline $\begin{array}{l}\text { Stuttering } \\
\text { group }\end{array}$ & Severity & $\begin{array}{c}\text { Mean \% }(S D) \\
\text { of stuttering on } \\
\text { content words }\end{array}$ & $\begin{array}{l}\text { Mean \% }(S D) \\
\text { of stuttering on } \\
\text { function words }\end{array}$ & $t$ & $d f$ & $\begin{array}{l}p \text { (two- } \\
\text { tailed) }\end{array}$ \\
\hline \multirow[t]{3}{*}{$\begin{array}{l}\text { Preschool } \\
(n=24)\end{array}$} & Mild $(n=5)$ & $9.4 \%(2.6)$ & $9.8 \%(6.4)$ & 0.09 & 4 & .926 \\
\hline & Moderate $(n=15)$ & $17.3 \%(9.4)$ & $19.4 \%(6.9)$ & 0.80 & 14 & .436 \\
\hline & Severe $(n=4)$ & $22.0 \%(5.7)$ & $30.3 \%(17.5)$ & 0.74 & 3 & .515 \\
\hline \multirow[t]{3}{*}{$\begin{array}{l}\text { School-age } \\
(n=61)\end{array}$} & Mild $(n=37)$ & $8.2 \%(4.4)$ & $11.8 \%(6.8)$ & 2.72 & 36 & .010 \\
\hline & Moderate $(n=18)$ & $30.3 \%(68.6)$ & $22.0 \%(10.3)$ & 0.57 & 17 & .573 \\
\hline & Severe $(n=6)$ & $35.9 \%(7.2)$ & $42.4 \%(21.8)$ & 0.31 & 5 & .808 \\
\hline
\end{tabular}


Figure 1. Mean Percentage of Stuttering on Function Words in School-Age Children Who Stutter Based on Severity

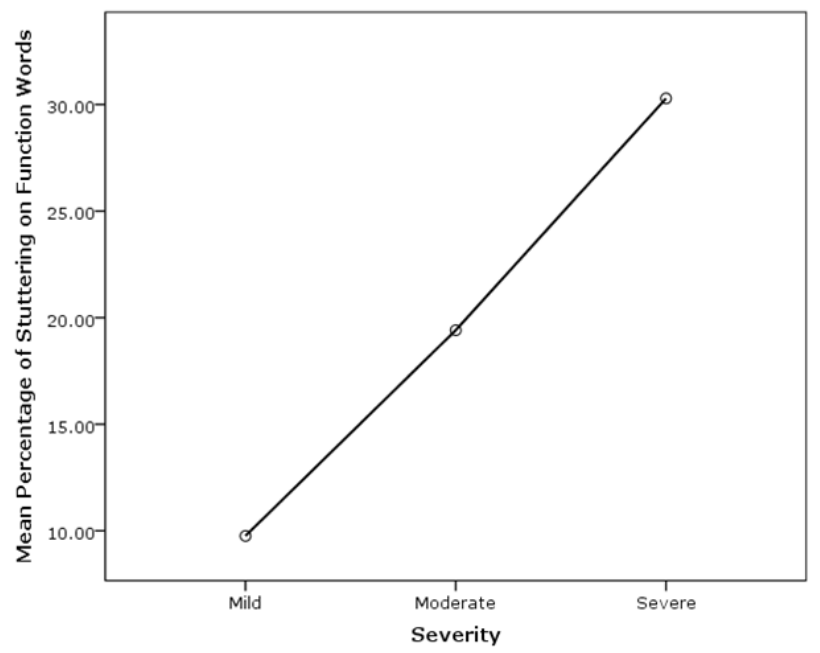

Figure 2. Mean Percentage of Stuttering on Function Words in Preschool Children Who Stutter Based on Severity

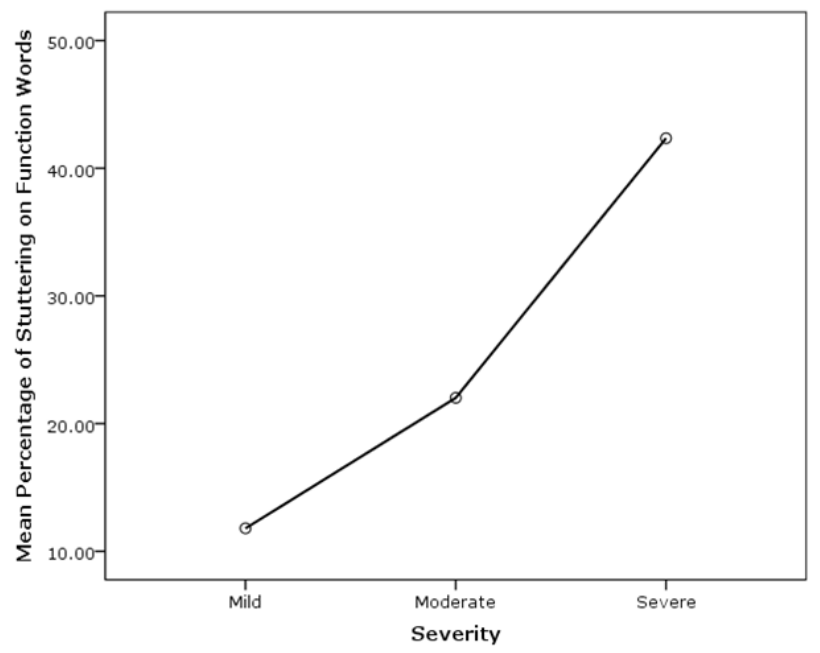

of stuttering on both content and function words between preschool and school age children who stutter were not statistically significantly different. It was also revealed that the difference in the mean percentage of stuttering between content versus function words in the levels of severity (mild, moderate, and severe) was not statistically significant in preschool children who stutter, whereas a higher siginificant percentage of stuttering on function words was shown in the mild level of stuttering for school age children who stutter. Further statistical analyses showed a significant positive correlation between SSI-4 scores of severity as a 
continuous variable and loci of stuttering on both content words and function words. Results also showed a significant negative correlation between age as a continuous variable and the loci of stuttering in the category of function words.

It was hypothesized by Au-Yeung et al. (1998) that dysfluencies in the speech of people who stutter typically occur on function words when function words precede, rather than follow, content words. It is assumed that these kinds of dysfluencies on function words occur because the plan for the following content word is not prepared for execution. To complete the required plan for the content word, disfluencies of repetition and hesitation on the preceding function words occur in order to take more time to finish such plan. Therefore, stuttering on function words is a delaying technique used by the speakers in an attempt to produce the subsequent content word fluently.

Looking at the position of content words in relation to the function words in the findings of the current study, it was revealed that that the percentage of dysfluencies on function words that occurred after the content word was very low, at $15 \%$ (48 function words with disfluency/320 total function words that occur after content), whereas the percentage of disfluencies on function words that occured before content words was very high, at 100\% (60 function words with disfluency/60 total function words occur before content).

Another interpretation for the role of the delaying strategy in justifying the findings of the current study is to examine the type of disfluencies on the function words that precede content words. If these disfluencies were repetitions or hesitations, it is more likely that the following content word would be produced fluently because of the use of execution delay appropriately. Conversely, if the function words that precede content words produced fluently or showed types of disfluencies other than repetitions or hesitations, then the delaying strategy did not work and, accordingly, the following content word would be produced disfluently. In the current study, the type of disfluencies that most commonly appeared on the function words before content words were repetitions (53.3\%). This has been reported previously by Au-Yeung et al. (1998) who claimed that content words that follow function words are the main cause of the delay (disfluency) in the preceding function words.

Regarding age, it is hypothesized that speakers who stutter stop using the delaying strategy over time, which means that the loci of stuttering on content words and function words will differ between age groups. The younger the people who stutter, the higher the frequency of stuttering on function words due to the use of the delaying strategy. This assumption is supported by the findings of the current study, where a significant negative correlation was found between age as a continuous variable and the percentages of stuttering on function words. On the other hand, according to the delaying strategy, the frequency of stuttering on content words increases as people who stutter get older because they stop using the delaying strategy. Thus, more disfluent moments appear on content words of the speech of older people who stutter because the required plan for the fluent 
production of such words is incomplete (Howell et al., 1999). This hypothesis is partially supported the findings of the current study. Although the values were not significant, it was observed that the mean percentage of stuttering on the content words of preschool children (16.5\%) lower than the mean percentage of stuttering on content words of school age children who stutter $(17 \%)$, whereas the mean percentage of stuttering on function words of preschool children who stutter (19.2\%) was higher than the mean percentage of stuttering of function words in school age children who stutter (16.5\%).

There were some limitations that might be controlled in future studies. First, there was a large gap in the severity levels with mild severity being observed in almost half of the school age group. Future studies could control the severity or increase the sample size, decreasing the gap among severity ratings. Second, the participants were divided into two age groups, preschool and school age, based on the previous hypothesis of the difference between the two groups in the loci of stuttering. This made the age range for school age participants rather large (6-16 years). Further studies with more classifications of age are needed.

\section{Conclusion}

This study explored the frequency of stuttering in content versus function words in spontaneous speech of preschool and school age children who stutter. Results showed no significant differences between function words and content words in preschool and school age children who stutter. For levels of stuttering, results indicated a higher siginificant loci of stuttering on function words compared to content words in the mild level of stuttering for school age children who stutter. The findings of the current study provide some basic important information about the distribution of the classical loci variables in disfluent utterences/words. Therefore, examining such topics contributes to the existing knowledge regarding the influence of linguistic factors such as word type (content vs. function) and stuttering frequency. 


\section{Acknowledgments}

The authors would like to thank the participants and their families who were cooperative in collecting the data and recording speech samples.

\section{Conflict of Interest Disclosure}

The authors declare that they have no conflict of interest.

\section{Funding}

The authors declare no sources of funding.

\section{Research Ethics Statement}

This study has been approved by the Institutional Review Board at Jordan University of Science and Technology (Ref \# 3/113/2018). 


\section{References}

Abdalla, F., Robb, M., \& Al-Shatti, T. (2010). Stuttering and lexical category in adult Arabic speakers. Clinical Linguistics and Phonetics, 24(1), 70-81. https://doi.org/10.3109/02699200903420316

Alm, P. A. (2004). Stuttering, emotions, and heart rate during anticipatory anxiety: A critical review. Journal of Fluency Disorders, 29(2), 123-133. https://doi.org/10.1016/j.jfludis.2004.02.001

Al-Tamimi, F., Khamaiseh, Z. \& Howell, P. (2013). Phonetic complexity and stuttering in Arabic. Clinical Linguistics and Phonetics, 27(12), 874-887. https://doi.org/10.3109/02699206.2013.823242

Arenas, R. M. (2012). The role of anticipation and an adaptive monitoring system in stuttering: A theoretical and experimental investigation [Doctoral dissertation, University of Iowa]. Iowa Research Online. http://ir.uiowa.edu/ etd $/ 2812 /$

Attieh, A. (2010). Linguistic factors affecting the loci and frequency of stuttering across age group among Arabic-speaking Jordanians. Journal of the Royal Medical Services, 17(3), 10-19.

Au-Yeung, J., Howell, P., \& Pilgrim, L. (1998). Phonological words and stuttering on function words. Journal of Speech, Language, and Hearing Research, 41(5), 1019-1030. https://doi.org/10.1044/jslhr.4105.1019

Bard, E., \& Anderson, A. H. (1983). The unintelligibility of speech of children. Journal of Child Language, 10(2), 265-292. https://doi.org/10.1017/ S0305000900007777

Bergmann, G. (1986). Studies in stuttering as a prosodic disturbance. Journal of Speech and Hearing Research, 29(3), 290-300. https://doi.org/10.1044/ jshr.2903.290

Bloodstein, O., \& Grossman, M. (1981). Early stutterings: Some aspects of their form and distribution. Journal of Speech, Language, and Hearing Research, 24(2), 298-302. https://doi.org/10.1044/jshr.2402.298

Boudelaa, S., \& Marslen-Wilson, W. D. (2001). Morphological units in the Arabic mental lexicon. Cognition, 81(1), 65-92. https://doi.org/10.1016/ S0010-0277(01)00119-6

Brocklehurst, P. H., Lickley, R. J., \& Corley, M. (2013). Revisiting Bloodstein's Anticipatory Struggle Hypothesis from a psycholinguistic perspective: A Variable Release Threshold hypothesis of stuttering. Journal of Communication Disorders, 46(3), 217-237. https://doi.org/10.1016/j. jcomdis.2013.04.002

Brown, S. F. (1945). The loci of stutterings in the speech sequence. Journal of Speech Disorders, 10(3), 181-192. https://doi.org/10.1044/jshd.1003.181

Brown, R., \& Fraser, C. (1963). The acquisition of syntax. In N. C. Cofer \& B. Musgrave (Eds.), Verbal behavior and learning: Problems and processes (pp. 158-201). McGraw-Hill. 
Dayalu, V. N., Kalinowski J., Stuart A., Holbert, D., \& Rastatter, M. P. (2002). Stuttering frequency on content and function words in adults who stutter: A concept revisited. Journal of Speech, Language, and Hearing Research, 45(3), 871-878. https://doi.org/10.1044/1092-4388(2002/070)

Dayalu V. N., Kalinowski J., \& Stuart. (2005). Stuttering frequency on meaningful and non-meaningful words in adults who stutter. Folia Phoniatrica Logopedica, 57(4), 193-201. https://doi.org/10.1159/000085187

Di Iorio, C. K. (2005). Measurement in health behavior. Methods for research and evaluation. Jossey-Bass.

Halpern, J. (2009, April). Word stress and vowel neutralization in modern standard Arabic [Conference presentation]. 2nd International Conference on Arabic Language Resources and Tools, Cairo, Egypt.

Hegde, M. N. (1970). Propositional speech and stuttering. Journal of All India Institute of Speech and Hearing, 1, 21-24.

Howell, P., Au-Yeung, J., \& Sackin, S. (1999). Exchange of stuttering from function words to content words with age. Journal of Speech, Language, and Hearing Research, 42(2), 345-354. https://doi.org/10.1044/jslhr.4202.345

Koopmans, M., Slis, I., \& Rietveld, T. (1991). The influence of word position and word type on the incidence of stuttering. In H. F. M. Peters, W. Hulstijn, \& C. W. Starkweather (Eds.), Speech motor control and stuttering (pp. 333-340). Elsevier.

Marshall, C. R. (2004). The morpho-phonological interface in children with specific language impairment [Unpublished doctoral dissertation]. University of London.

Martin, R.R., \& Haroldson, S.K. (1981). Stuttering identification: Standard definition and moment of stuttering. Journal of Speech and Hearing Research, 24(1), 59-63. https://doi.org/10.1044/jshr.2401.59

Natke, U., Grosser, J., Sandrieser, P., \& Kalveram, K. (2002). The duration component of the stress effect in stuttering. Journal of Fluency Disorders 27(4), 305-318. https://doi.org/10.1016/S0094-730X(02)00163-8

Wingate, M. E. (1964). A standard definition of stuttering. Journal of Speech Hearing Disorders, 29(4), 484-489. https://doi.org/10.1044/jshd.2904.484

Wingate, M. E. (1979). The first three words. Journal of Speech and Hearing Research, 22(3), 604-612. https://doi.org/10.1044/jshr.2203.604

Yairi, E. (1997). Disfluency characteristics of childhood stuttering. In R. F. Curlee \& G. M. Siegel (Eds), Nature and treatment of stuttering (pp. 49-78). Allyn \& Bacon.

Yaruss, J. S. (1997). Clinical measurement of stuttering behaviors. Contemporary Issues in Communication Science and Disorders, 24(Spring), 27-38. https:// doi.org/10.1044/cicsd_24_S_27 


\section{Appendix}

\begin{tabular}{|c|c|c|c|c|c|c|}
\hline \multicolumn{7}{|c|}{ Table A1. Characteristics of the Participants } \\
\hline Participant & Age & Gender & Diagnosis & Age group & SSI score & $\begin{array}{c}\text { Severity } \\
\text { rating }\end{array}$ \\
\hline 1 & 4 & $\mathrm{~F}$ & Developmental stuttering & Preschool & 24 & Moderate \\
\hline 2 & 5 & $\mathrm{~F}$ & Developmental stuttering & Preschool & 15 & Mild \\
\hline 3 & 5 & M & Developmental stuttering & Preschool & 16 & Mild \\
\hline 4 & 5 & M & Developmental stuttering & Preschool & 27 & Severe \\
\hline 5 & 5 & M & Developmental stuttering & Preschool & 30 & Severe \\
\hline 6 & 4 & M & Developmental stuttering & Preschool & 22 & Moderate \\
\hline 7 & 5 & $\mathrm{~F}$ & Developmental stuttering & Preschool & 24 & Moderate \\
\hline 8 & 4 & M & Developmental stuttering & Preschool & 23 & Moderate \\
\hline 9 & 5 & M & Developmental stuttering & Preschool & 16 & Mild \\
\hline 10 & 4 & M & Developmental stuttering & Preschool & 23 & Moderate \\
\hline 11 & 4 & $\mathrm{~F}$ & Developmental stuttering & Preschool & 31 & Severe \\
\hline 12 & 5 & M & Developmental stuttering & Preschool & 25 & Moderate \\
\hline 13 & 5 & M & Developmental stuttering & Preschool & 14 & Mild \\
\hline 14 & 5 & M & Developmental stuttering & Preschool & 24 & Moderate \\
\hline 15 & 4 & M & Developmental stuttering & Preschool & 21 & Moderate \\
\hline 16 & 5 & M & Developmental stuttering & Preschool & 21 & Moderate \\
\hline 17 & 5 & $\mathrm{~F}$ & Developmental stuttering & Preschool & 24 & Moderate \\
\hline 18 & 5 & M & Developmental stuttering & Preschool & 25 & Moderate \\
\hline 19 & 4 & $\mathrm{~F}$ & Developmental stuttering & Preschool & 13 & Mild \\
\hline 20 & 5 & M & Developmental stuttering & Preschool & 29 & Severe \\
\hline 21 & 4 & M & Developmental stuttering & Preschool & 21 & Moderate \\
\hline 22 & 4 & $\mathrm{~F}$ & Developmental stuttering & Preschool & 26 & Moderate \\
\hline 23 & 5 & M & Developmental stuttering & Preschool & 26 & Moderate \\
\hline 24 & 4 & M & Developmental stuttering & Preschool & 22 & Moderate \\
\hline 25 & 11 & M & Developmental stuttering & School-age & 15 & Mild \\
\hline 26 & 12 & M & Developmental stuttering & School-age & 17 & Mild \\
\hline 27 & 10 & M & Developmental stuttering & School-age & 21 & Moderate \\
\hline 28 & 6 & M & Developmental stuttering & School-age & 19 & Mild \\
\hline 29 & 10 & M & Developmental stuttering & School-age & 24 & Moderate \\
\hline 30 & 15 & M & Developmental stuttering & School-age & 32 & Severe \\
\hline 31 & 10 & M & Developmental stuttering & School-age & 20 & Mild \\
\hline 32 & 15 & M & Developmental stuttering & School-age & 11 & Mild \\
\hline 33 & 10 & M & Developmental stuttering & School-age & 30 & Severe \\
\hline 34 & 15 & M & Developmental stuttering & School-age & 20 & Mild \\
\hline 35 & 14 & M & Developmental stuttering & School-age & 22 & Moderate \\
\hline 36 & 8 & M & Developmental stuttering & School-age & 19 & Mild \\
\hline 37 & 10 & M & Developmental stuttering & School-age & 32 & Severe \\
\hline 38 & 13 & M & Developmental stuttering & School-age & 20 & Mild \\
\hline 39 & 13 & M & Developmental stuttering & School-age & 17 & Mild \\
\hline 40 & 10 & M & Developmental stuttering & School-age & 17 & Mild \\
\hline 41 & 8 & M & Developmental stuttering & School-age & 21 & Moderate \\
\hline 42 & 12 & $\mathrm{~F}$ & Developmental stuttering & School-age & 24 & Moderate \\
\hline 43 & 7 & $\mathrm{~F}$ & Developmental stuttering & School-age & 28 & Severe \\
\hline
\end{tabular}


Characteristics of the Participants (cont.)

\begin{tabular}{|c|c|c|c|c|c|c|}
\hline Participant & Age & Gender & Diagnosis & Age group & SSI score & $\begin{array}{c}\text { Severity } \\
\text { rating }\end{array}$ \\
\hline 44 & 9 & M & Developmental stuttering & School-age & 21 & Moderate \\
\hline 45 & 10 & M & Developmental stuttering & School-age & 21 & Moderate \\
\hline 46 & 12 & M & Developmental stuttering & School-age & 13 & Mild \\
\hline 47 & 9 & M & Developmental stuttering & School-age & 19 & Mild \\
\hline 48 & 7 & $\mathrm{M}$ & Developmental stuttering & School-age & 19 & Mild \\
\hline 49 & 12 & $\mathrm{~F}$ & Developmental stuttering & School-age & 13 & Mild \\
\hline 50 & 14 & M & Developmental stuttering & School-age & 21 & Moderate \\
\hline 51 & 16 & M & Developmental stuttering & School-age & 23 & Moderate \\
\hline 52 & 9 & M & Developmental stuttering & School-age & 11 & Mild \\
\hline 53 & 10 & M & Developmental stuttering & School-age & 22 & Moderate \\
\hline 54 & 16 & M & Developmental stuttering & School-age & 13 & Mild \\
\hline 55 & 12 & M & Developmental stuttering & School-age & 14 & Mild \\
\hline 56 & 7 & M & Developmental stuttering & School-age & 14 & Mild \\
\hline 57 & 11 & M & Developmental stuttering & School-age & 24 & Moderate \\
\hline 58 & 13 & M & Developmental stuttering & School-age & 11 & Mild \\
\hline 59 & 13 & M & Developmental stuttering & School-age & 12 & Mild \\
\hline 60 & 10 & M & Developmental stuttering & School-age & 25 & Moderate \\
\hline 61 & 8 & M & Developmental stuttering & School-age & 25 & Moderate \\
\hline 62 & 9 & M & Developmental stuttering & School-age & 12 & Mild \\
\hline 63 & 13 & M & Developmental stuttering & School-age & 29 & Severe \\
\hline 64 & 9 & M & Developmental stuttering & School-age & 14 & Mild \\
\hline 65 & 10 & M & Developmental stuttering & School-age & 15 & Mild \\
\hline 66 & 12 & M & Developmental stuttering & School-age & 15 & Mild \\
\hline 67 & 11 & M & Developmental stuttering & School-age & 21 & Moderate \\
\hline 68 & 14 & M & Developmental stuttering & School-age & 14 & Mild \\
\hline 69 & 8 & M & Developmental stuttering & School-age & 11 & Mild \\
\hline 70 & 8 & M & Developmental stuttering & School-age & 22 & Moderate \\
\hline 71 & 16 & M & Developmental stuttering & School-age & 19 & Mild \\
\hline 72 & 6 & M & Developmental stuttering & School-age & 14 & Mild \\
\hline 73 & 7 & $\mathrm{M}$ & Developmental stuttering & School-age & 12 & Mild \\
\hline 74 & 9 & M & Developmental stuttering & School-age & 12 & Mild \\
\hline 75 & 9 & M & Developmental stuttering & School-age & 11 & Mild \\
\hline 76 & 15 & M & Developmental stuttering & School-age & 17 & Mild \\
\hline 77 & 13 & M & Developmental stuttering & School-age & 15 & Mild \\
\hline 78 & 12 & M & Developmental stuttering & School-age & 19 & Mild \\
\hline 79 & 7 & M & Developmental stuttering & School-age & 16 & Mild \\
\hline 80 & 12 & M & Developmental stuttering & School-age & 23 & Moderate \\
\hline 81 & 7 & $\mathrm{~F}$ & Developmental stuttering & School-age & 22 & Moderate \\
\hline 82 & 12 & $\mathrm{~F}$ & Developmental stuttering & School-age & 17 & Mild \\
\hline 83 & 10 & M & Developmental stuttering & School-age & 21 & Moderate \\
\hline 84 & 6 & M & Developmental stuttering & School-age & 33 & Severe \\
\hline 85 & 7 & $\mathrm{M}$ & Developmental stuttering & School-age & 11 & Mild \\
\hline
\end{tabular}

